\title{
Progress of In-situ Study on Mechanical Properties for Micro/nano-structured Alloy
}

\author{
Jie Sheng ${ }^{1,2}$, Peiqing La 1,3, , Junqiang Ren ${ }^{3}$, Jiqiang Ma ${ }^{3}$, Yu Shi ${ }^{1}$, Zhengning Li ${ }^{1}$, Fuan Wei ${ }^{4}$, \\ Keliang Wang ${ }^{1}$ and Yi Song ${ }^{1}$
}

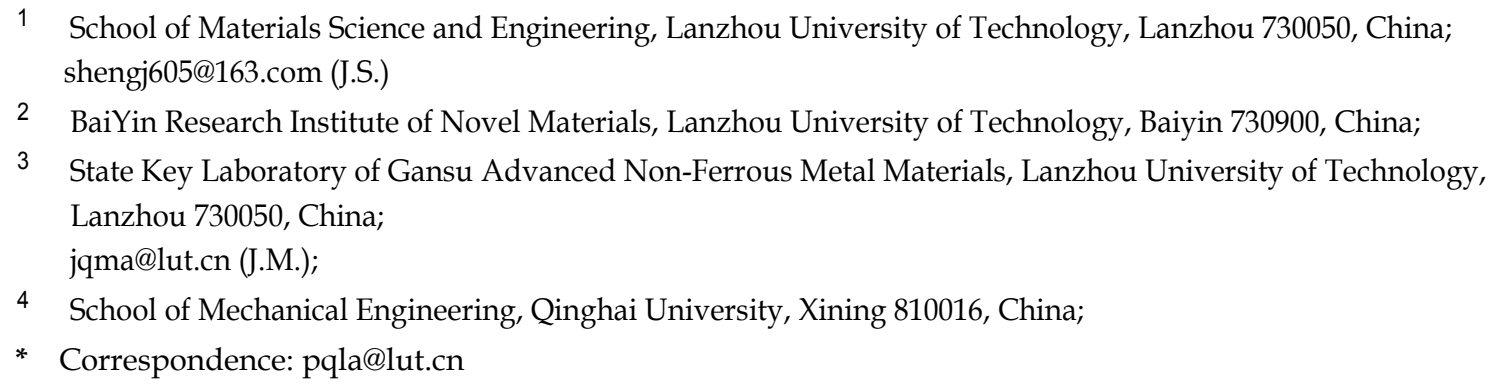

\begin{abstract}
Metal and alloy toughening was the core and long-term research direction in materials filed. As grain size had bimodal distribution, micro/nano-structured alloys presented excellent comprehensive mechanical properties, and this had become one of the research hotspots and developing trends in the field of nanotechnology. In-situ tensile test was a direct and effective method to study the deformation mechanism of materials, which revealed the multiple mechanisms responding to feature grain sizes and provided reliable experimental means and research technique. Research on development of in-situ technique and its applications in mechanical properties was reviewed in this paper according to the recent advances on the modern mechanical properties for high strength and high plasticity alloy at home and abroad. The disadvantages of the present study of preparation methods and investigation techniques for high-performance alloy had been concluded. Finally, the development prospects of high strength and high plasticity alloy materials were analyzed.
\end{abstract}

Keywords: micro/nano-structured alloy; mechanical properties; in-situ tensile; deformation mechanism; research progress

\section{Intorduction}

Micro/nano-structured alloy materials were referred to the bulk alloy of single-phase or multiphase material, in which grain size range with micrometer and nanoscale followed statistical bimodal distribution. Because of its special morphology, micro/nano-structured alloy had excellent mechanical properties compared with conventional coarse-grained (CG) materials [1-4]. Ductility ratio of most nanostructure metal was relatively low (generally less than $2 \%$ ) at room temperature (RT). In which grain size was less than $25 \mathrm{~nm}$. And ductility ratio was decreased with grain size decreasing [5]. The material grain size was range of between 1-10 $\mu$ m usually had moderate strength and good plasticity, and nanocrystalline materials had high strength and limited plasticity. Therefore, inhomogeneous nanostructures could effectively make up the deficiency of strain hardening for nanocrystalline [6,7], thus RT ductility would be improved. A point of view for heterogeneous composite material could obviously improve work hardening ability and ductility at RT was proposed by Y.M. Wang in 2002. Here, grain size of nanocrystalline and microcrystalline was bimodal distribution. Micro/nano-structured alloy showed various mechanisms corresponding to each feature size, which made overall performance and service behavior had been optimized and improved. It could be seen that the smaller size of the second-phase of the plasticized particles (micro) was embedded in the matrix with poor plasticity, thus, the overall plasticity of the alloy was greatly 
improved, as showed in Figure 1. The smaller size of the second-phase also had dispersion strengthening effect, which brought not only high strength and good plasticity.

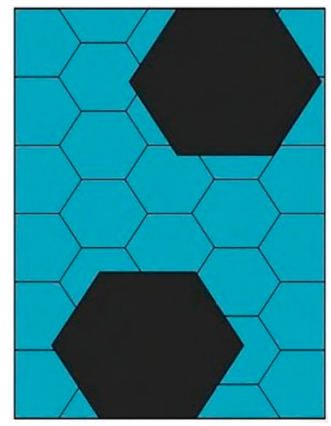

(a)

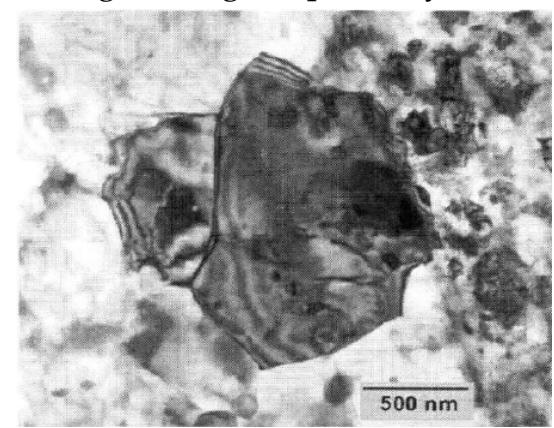

(b)

Figure 1. Typical bimodal distribution microstructure (a) schematics of bimodal grain size distributions [8]; (b) microcrystalline distributed in the nanocrystalline matrix [3]

\section{Research Development of Preparation and Mechanical Properties for High Strength and High Plasticity Alloy}

Deformation mechanism of nano-structured materials was dominated by dislocation leading to grain boundary. Dislocation emitted from one end of the grain boundary but soon mutually annihilated on the other side, and it was hard to be stored in grains. A large number of dislocations were introduced beforehand, due to large deformation in the preparation process of ultrafine-grained materials. It was easy to have dislocation tangle and caused difficulty for productive new dislocation in grains. Therefore, work hardening ability of micro/nano-structured materials was very poor, this resulted in low macroscopic uniform plasticity [2]. For this, a lot of experiment and research had been done to improve the ability of work hardening and plasticity for nanocrystalline/ultrafine-grained metallic materials. Many approaches had been reported for improving strain hardening $[9,10]$ and uniform tensile plasticity [11] at present. Nano-twin, precipitated phase/second-phase was introduced in homogeneous microstructure of nanocrystalline/ultrafine-grained, which grain size distribution was bimodal and plastic strain induced grain phase transformation/twinning deformation.

Tensile testing was conducted with crystalline and densification process for Al-4wt $\% \mathrm{Mg}$ alloy powder by V.K.Tellkamp [12]. It was found that yield strength and ultimate strength increased to nearly $30 \%$ than commercial $5083 \mathrm{Al}$ alloys and elongation had not fallen. There had been a lot of secondary particles $\left(\mathrm{AlN}, \mathrm{Al}_{2} \mathrm{O}_{3}\right)$ in the grain boundaries and by solute drag $\mathrm{Al}$ segregation at grain boundaries which was a prime cause of heat stability of properties and microstructure. D.Witkin [13] studied Al-7.5Mg powder, curtailing and then consolidation extrusion were utilized to produce bulk nano-structured materials, yield strength and tensile strength reached at $641 \mathrm{MPa}, 847 \mathrm{Mpa}$ respectively, tensile elongation of $8.4 \%$. Wang $[14,15]$ reported a way of low-temperature rolling and transient annealing to obtain pure $\mathrm{Cu}$ with bimodal distribution(micro sized grains were embedded in the nanocrystalline and ultra fine crystalline matrix) in Nature, grain size was mainly concentrated within these two ranges of less than $300 \mathrm{~nm}$ and far great than $1.5 \mu \mathrm{m}$. Grain size of coarse grain (CG) was $1-3 \mu \mathrm{m}$ accounted for $25 \%$, the rest was ultra fine grain with grain size less than $300 \mathrm{~nm}$. The tensile strength of specimens was maintained at $430 \mathrm{MPa}$ decreased a little compared with fully nanocrystalline copper, but tensile ductility was greatly improved and fracture elongation reached $65 \%$, uniform elongation was 30\%, which had approached plasticity of annealed CG copper at RT. Based on the result, they had first proposed solving low tensile ductility by realization of bimodal grain distribution, which had aroused widespread concern. The team used three methods were bimodal grain size distribution, inhibition of recovery at low temperature and high strain rate sensitivity of flow stress in ECAP copper to obtain large tensile deformation. Means of non-uniform structure that nano/micro-crystalline composite materials were presented to improve plasticity of nanocrystalline materials. K. Lu [16] developed nano-twin structured pure $\mathrm{Cu}$ with ultra high strength, high conductivity, and extreme value strength and work hardening effect were found. Zhao [17] introduced nano-sized precipitation in $7075 \mathrm{Al}$ alloys. Interior dislocation occurred in pinning and remained in antiparticle, which could improve both tensile strength and plasticity. 
Nano-twins were brought to antiparticle by K. Lu [18]. The interaction between twins and dislocations occurred and at the same time dislocations could be stored on the twin interface when they were in the plastic deformation. The yield strength of nano-structured $\mathrm{Cu}$ was up to $1068 \mathrm{MPa}$ which was 10 times higher than GC Cu, meanwhile with 13\% uniform elongation. Tao [19,20] adopted method of dynamic plastic deformation (DPD) and post annealing processes to compose a complex structure in 316L stainless steel, micron scale austenite grain dispersed and distributed in nanoscale twin beams (volume fraction 20\%). This kind of 316L stainless steel had tensile strength up to $1001 \mathrm{MPa}$, tensile elongation of $23 \%$. Such high strength came from significant number nano-twin beams, and the plasticity was attributed to the recrystallization grain. Micron scale static recrystallization grain (SRX, average grain size was $1.75 \mu \mathrm{m}$ occupied about $50 \%$ volume fraction) was prepared by means of DPD with high strain rate of F.K. Yan [21]. A complex structure of 316L austenite stainless steel was formed with partial nano-twins which occupied $24 \%$ volume fraction and nanocrystalline. Strength could get up to $945 \mathrm{MPa}$ (strength of nanocrystalline was $1400 \mathrm{MPa}$ ) and elongation rate increased from $10 \%$ to $27 \%$. S.M. Hosseini [22] found that the complex structure consisted with ultrafine-grain and CG could be obtained for short anneal time at high temperature in low carbon steel, the fracture strength of $810 \mathrm{MPa}$ and elongation of $16.8 \%$ in 2012 . Wu [23,24] and others suggested that nanocrystalline structure with grain size gradient distribution (GNS, gradient maintained structure, part of material was composed of nanostructures and other part was composed of CG structure, the size of structure unit was gradient continuous change between these two parts) was an effective way to improve the plasticity of nanocrystalline materials. Metal with GNS had a trans-scale grain size (range of from $10 \mathrm{~nm}$ to $25 \mu \mathrm{m}$ ). And if steel with gradient structure was prepared via surface mechanical attrition treatment. Huang [25] presented an ideal ultra fine grain structure produced by deformation induced martensite inverse transformation in 304L austenitic stainless steel. Fine grains and high density of nano-sized twins in this kind of structure had high strength and high plasticity. This method was applied to the metal with a face centered cubic and low stacking fault energy.

The researches at home and abroad showed that micro/nano-structure could improve obviously mechanical properties of alloy, and was one of the effective ways driven up mechanical properties of nanostructure materials. Microstructure was designed and controlled to activate deformation mechanism what we hoped. It was a long-term goal that the overall performance and service behavior of materials were optimized and improved to meet the needs of a wider and deeper scope of industrial applications for material researcher.

\section{Development of In-situ Technique on Electron Microscope}

The invention of various microscopes was the most important technology, which greatly promoted the development of neuroscience, as well as one of the core methods to do original research work. Limiting resolution of optical microscopy was on a spectrometer scale because of small size of nanostructures, so the variation of nanocrystalline structure was not detected. Therefore, microanalysis of micro/nano-structures was observed by means of high resolution electron microscopy. The first electronic microscope was born in 1933, and in-situ technology began to be used 3 years later. In-situ technology was limited by processing technology for a long time, and had been rapid development until nearly 5 years. It brought new opportunities through in-situ observation, while the accuracy of the electron microscope itself had reached a certain limit. After the addition of in-situ test means, it not only enriched methods of nanoresearch, but also widened the scope of nanoresearch.

\subsection{In-situ testing of mechanical properties}

Mechanical properties were an important index to evaluate synthetical properties of alloy[26], which were the main basis for various engineering design parameters [27]. Uniaxial tension was one of the most basic experimental methods to study mechanical properties had been used widely. Tensile properties were tested by universal material experimental machine. In-situ tensile investigated the mechanical behavior of high strength and high plasticity alloy from the micro scale, and provided the basis for development of microstructure [28,29]. The development and maturing of in-situ electron microscopy, high resolution electron microscopy had provided new opportunities 
for nanoscience. Cracks initiation and propagation were synchronous observed based on in-situ SEM/TEM technique. Experiment result of dynamic study on mechanical properties at a micro level was associated with application effect. It could provide a direct mechanism for improving the mechanical properties. Based on the combination of in-situ stretching device and microscope, change rule of macroscopic mechanical properties and misconstruction revealed. This was a powerful experimental method, and significant theoretically and practically to research mechanical properties.

Resolution of TEM and SEM reached sub-nanoscale and nanoscale respectively, which provided a new technical means of in-situ characterization for nanostructure materials [30]. Accordingly, in-situ observation usually carried out on an electron microscope. Due to load limitation specimen generally was non-standard, and loading rate was controlled. After materials appeared a crack, specimen was taken photos under loading conditions. In-situ observation for change in the microscopic structure of crack tip and relationship between crack growth path and microstructure were obtained, and the loading was applied in the form of displacement control solution on specimens step by step. As tensile loading applied, the whole process could be observed and recorded.

Table 1. Comparison between traditional uniaxial tension and in-situ tension

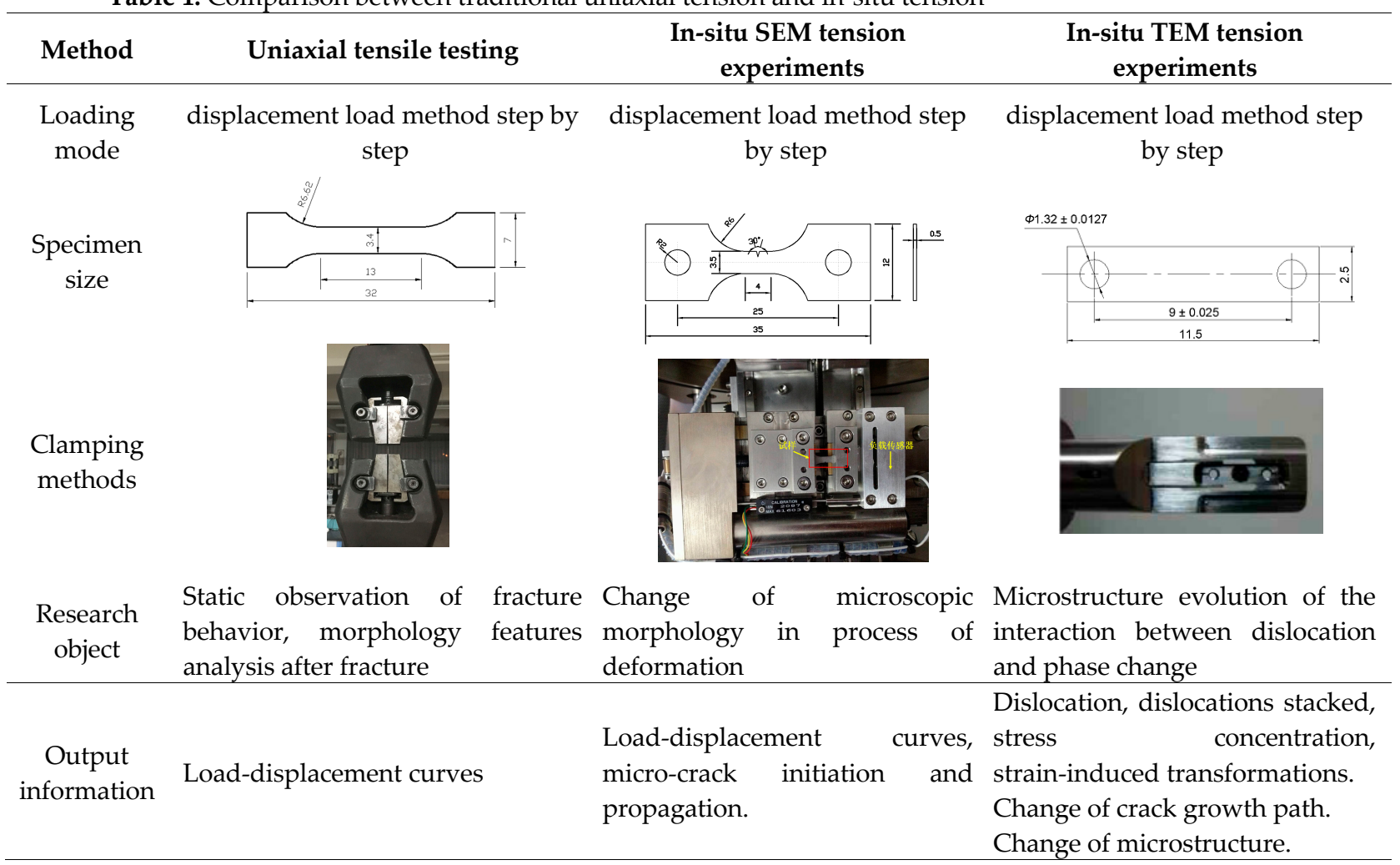

Microstructure such as morphology, chemical composition, crystal structure and mechanical properties was matched one-to-one by means of in-situ test technique to obtain experimental results could be more really reflect the relationship between microstructures and properties. This advanced research method provided a direct and reliable experimental data to have some insight into the transformation of microstructure [31-35]. With the further development of large scale integration (LSI), research on mechanical behavior of the alloy in microcosmic scale, it had great scientific meaning and extensive prospect. Micro mechanical behavior of material under test was conducted accurately on in-situ tension experiments. This was better for observation of fine crack initiation and propagation. In-situ tensile technique also revealed mechanical behavior, work hardening and microstructure deformation mechanism of multi-scale grain structure.

\subsection{In-situ SEM technology and development}

The late 1960s, in-situ SEM had become a new method to study mechanical properties [36,37]. Materials of loads until it broke were observed and recorded by in-situ dynamic tensile device of SEM that equipped internal motor drive, rotary decoder, the linear movement sensor, accomplished computer control and data collection [38,39]. Sensitivity to crack size and rate of growth could be 
studied by tensile stage of SEM under the condition of artificial pre-existing crack. Effect of microstructure, morphology, particle size and distribution of alloying on fracture could be observed. These were beneficial to research of fracture toughness and fracture behavior.

Tensile fracture behavior of Al-Li-Cu-Mg-Zr alloy was studied by in-situ observation using SEM [40]. The main cause of intergranular fracture of Al-Li based alloy was severely weakened grain boundary during aging treatment. Dynamic growth of pure $\mathrm{Fe}$, Ni oxide whisker and oxidation mechanism were studied using in-situ SEM observation on high temperature by Shao [41,42]. Jiang [43] in-situ analyzed changes of microstructure and fracture process of the evolutionary process and studied microstructure evolution and fracture mechanism of TWIP steel. Ren[44] used in-situ observed by SEM to study retaining ring austenitic stainless steel $1 \mathrm{Mn} 18 \mathrm{Cr} 18 \mathrm{~N}$. The results showed that the main deformation mechanism was slip and twinning. With the deformation increasing, slip-line was gradually increased and broadened. At the per-cracks was likely to cause stress concentration which would be produced micro-cracks, and finally resulted in the fracture failure.

\subsection{In-situ TEM mechanical testing}

In-situ transmission electron microscopy (TEM) method is powerful in a way that it can directly correlate the atomic-scale structure with physical and chemical properties. It played a powerful role in the microstructure characterization of TEM. There was a one-to-one correspondence between microstructure and mechanism properties for nano-structured materials. It guided and promoted functional new materials. The beginning of the last century in 50s, TEM was utilized to study dislocation and twin or other static structure and its change of dynamic process. Micro tensile testing device could be installed limited sample space ( $3 \mathrm{~mm}$ by $15 \mathrm{~mm}$ by $2 \mathrm{~mm}$ ) in 1990 s. Resolution of stress test and deformation response was simultaneously satisfied. It gradually becomes common testing means to study micro structural development and restrictive process and mechanism [45]. With the continuous development of electronic microscopy, resolution of TEM could reach 50pm, which applied field such as force, electric, thermal, magnetic optical field. It provided various performance to in-situ to observe and sample tests [46], as shown in Figure 2.

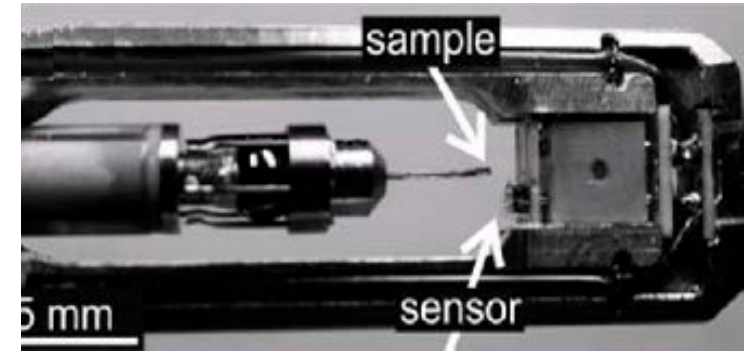

Figure 2. Sample rod of in-situ mechanics produced by Sweden Nanofactory Company [47]

With the rapid development of in-situ TEM, that was utilized in scientific research such as physical/chemical characterization on the atomic scale, low-dimensional nonstructural for manipulating the physics properties by adding external field more and more widely [48]. It was shown that the present research provided a comprehensive understanding of the mechanical properties of composite, establishment of physical models of plastic deformation and guiding the preparation process of new material. In the early 1980s, in-situ TEM tension experiments were first carried out by S.M. Oh at the Oak Ridge National Laboratory [49,50]. Mo, W, Al, Cu was taken into research objects, dislocations motion at the crack tip and micro-cracks propagation of dynamic process was observed. In tension processes, a partial dislocation with low stock fault had slipped at the crack tip and stayed at the original glide plane of coplanar to cracks. However, dislocation with high stock fault at crack tip slipped out original glide plane formed wide deformation zone to dislocation-free zone ahead of the crack tip. Research of TEM in-situ tension was concerted on dislocation behavior at the early of 1990s. Yao from Tsinghua University [51] investigated plastic deformation process of crack tips and dislocation distribution in dual phase steel. The study found that areas of dislocation-free zone were large and it was likely to happen cross-slipping to a larger plastic-zone of the ferrite phase. Meanwhile, area of dislocation-free zone was small in at austenite, and crack tip emitted the dislocations which more prone to reverse blocking. Moving dislocation mechanism of Fe-31.1Mn-6.1Si shape memory alloy was investigated via method in-situ SEM 
observation in a high voltage electron microscope (HVEM) by Y. Hoshino [52]. In order to explain the mechanism of partial dislocation movement in Fe-Mn-Si shape memory alloy, formation mechanism of $\varepsilon$ martensite was studied. It turned out that the small angle grain boundary was composed of three complete dislocations, dislocation source was played by a polar mechanism. H. Fujita [53] studied Fe-Cr-Ni alloy through in-situ tensile testing, and found a martensite (hard phase) formation mechanism. Xie [54] investigated medium manganese austenite steel via TEM in-situ tensile. The search found that lath induced martensite nucleated at high density dislocation region and increased with the increment of strain. Cracks were restricted or stop propagated at high density dislocation region, second phase particles and strain induced martensite. This revealed the internal cause of work-hardening for medium manganese steel. Wu [55] used TEM to study 316L austenitic stainless steel with grain size of bimodal distribution. The source of grain size of bimodal distribution in austenite was deduced, that grains on micro-scale came from recrystallization of deformed austenite with non deformation during cold forming, and grains on submicro-scale mainly originated from strain-induced martensitic inverse transformation. Martensitic transformation was observed of SUS304 metastable austenite stainless steel in tensile process by Li [56]. $\varepsilon$ Martensite platelets are preferentially induced from the sites of dislocation pile-ups, and the strain-induced transformation and stress-induced transformation can co-exist. Wang [57] took pure was objective and systematic studied deformation mechanism on a small scale in bcc metal adopting in-situ testing. This was the first time to find deformation twins at low strain under ambient condition for $\mathrm{cc}$ metals. It made the big breakthrough of research on deformation mechanisms at the microscopic scale. Zhang [58] searched crack initiation and propagation of 3104 aluminium alloys in dynamic stretching process. The results showed that cracks initiated in slip bands, and expanded along slip bands. Propagation path was influenced tensile stress state, grains in the sheet and distribution of coarse second phase. Sui [59] made a special bimetallic strip stretcher to in-situ tension along with

direction of [2110] for single crystals. The experimental results indicated that three different kinds Burgers vectors of slip dislocation were produced successively as the strain increases. Shan [60] used in-situ mechanical testing by ETEM analysis, made a significant breakthrough in research of hydrogen embitterment again. Hydrogen not only caused pinning due to dislocation in aluminum, but also this process was reversible.

So for in-situ TEM was applied in new nano materials such as grapheme, carbon nanotubes and had a crucial component in research.

\section{Insufficiency in the Existing Preparation and Developing Technique}

Technique of in-situ loading was the most convenient and intuitive observation equipment for observation of fracture behavior under tensile loading. There were also some defects, such as expensive cost of SEM/TEM caused much less popular, limited size of the loaded cavity further increased cost, specificity of specimen preparation.

The structure and size of nanomaterials were one of the most important factors to determine their physical and chemical properties, so the growth and preparation of nanomaterials had long been compelling. Through several decades of years, a large number of nanomaterials had been prepared. All the same, most growth mechanism was still being-written. The growth of nanomaterials with controllable size and morphology was still a difficult problem and a hot issue in material science [47]. Through comparing and analyzing the existing new technique and process of preparation of high strength and high plasticity alloy, by which materials with excellent mechanical properties could be obtained. Each of these had its own characteristic. But we also recognize that most equipment of preparation technology of was expensive, manufacturing technique was complicated, and repeatability was not good, which was at the stage of laboratory research. Alloy of block materials with high strength and high plasticity preparation technology which would be perfected and optimized. So far, relevant studies of micro/nano-structure were pin-points at home and abroad, and there was no systemic study of mechanical properties. The effect of mechanical properties on the grain boundary of nanocrystalline, crystal defects was discussed. Further studies were needed to understand the deformation mechanism of micro/nano-structured materials. The reason was that preparation methods were limited. It was difficult to prepare bulk alloy specimen which chemical composition was pure and grain size distribution was bimodal. To establish 
deformation mechanism, this was the key to obtain pure, dense bulk alloys. The complete dandified bulk alloys were still lacking in the existed literature to test performance. La P.Q. presented a new way of preparation method named aluminothermic reaction(AR) on grain size was bimodal distribution and controllable[61-63]. Bulk alloy was prepared by AR. The diameter was larger than $100 \mathrm{~mm}$ and thickness was more than $10 \mathrm{~mm}$. Large bulks materials would help exploration and development of mechanical properties and special deformation mechanism at a further level.

\section{Conclusions and Prospects}

In-situ observation and microanalysis can be achieved in the tensile process by SEM/TEM in-situ tension. Some important phenomena and law are concluded, and it is one of the effective measures to study the deformation mechanism. At present, in-situ tension has been widely applied in research on mechanical behavior and microstructure as alloy. The deformation mode at the microscopic scale under different strain conditions, for instance, rotation, sliding and fracture of grain orientation can be observed to study micro-mechanism of fracture in alloy. Deformation mechanism of micro/nano-structured alloy, designing of microstructure on trans-scale, developing new microstructure mechanics and engineering application will play a very important role. Through the studying of deformation mechanisms on micro-scale for micro/nano-structured alloy by which existing theory system of metal deformation will be broadened, development and application of an alloy with high performance will be guided. There is strong theoretical and practical significance.

Acknowledgments: This work was supported from National Natural Science Foundation of China (51561020).

Author Contributions: Jie Sheng prepared a lot of literatures and wrote the paper; Peiqing La provided research funding support; Junqiang Ren, Jiqiang Ma and Yu Shi performed in-situ TEM tension experiments; Zhengning $\mathrm{Li}$ and Fuan Wei carried out mechanical properties; Keliang Wang and Yi Song was responsible for the preparation and characteristics of the samples. The manuscript was written through the contribution of all authors.

Confilcts of Interest: High strength and toughness nanocrystalline stainless steel

\section{References}

1. Zhu, Y.; Liao, X. Nanostructured metals: retaining ductility. Nature Mater. 2004, 3, 351-352.

2. Zhang, C.X. Mechanical properties and strain hardening of gradient nanostructure nickel. Taiyuan University of Technology, Taiyuan, 2015.

3. Xia, S. Investigation on ductilization by composite on micro-size/ultrafine-grained microstructure. Nanjing University of Science and Technology, Nanjing, 2010.

4. Bai, Z.; Zhang, Z.; Dai, Y.; Zhou, J.; Zhang, S. Research progress in mechanical properties of bulk nanocrystalline metals. Mater. Rev. 2009, 23, 50-54.

5. Koch, C.; Morris, D.; Lu, K.; Inoue, A. Ductility of nanostructured materials. Mrs Bull. 1999, 54-58.

6. Chen, L. Mechanical properties and strain hardening behavior of dual-phase nanostructured metallic materials, Institute of Mechanics. Chinese Academy of Sciences, Beijing, 2012.

7. Lei, W. Preparation and mechanical properties of ultrafine-grained low-carbon steel with high strength and high ductility. Yanshan University, Qinhuangdao, 2010.

8. Liu, Y.; Ju, R.; Li, H.; Zhao, G. Constitutive behavior of bimodal nanocrystalline materials. Chin. J. Mater. Res. 2015, 29, 889-894.

9. Challa, V.; Wan, X.; Somani, M.; Karjalainen, L.; Misra, R. Strain hardening behavior of phase reversion-induced nanograined/ultrafine-grained (NG/UFG) austenitic stainless steel and relationship with grain size and deformation mechanism. Mater. Sci. Eng., A 2014, 613, 60-70.

10. Chen, $\mathrm{K}$. The research on strain hardening mechanism of twinning induced plasticity (TWIP) steel with heterogeneous lamellar structure. University of Chinese Academy of Sciences, Beijing, 2016.

11. Kong, F.; Chen, Z.; Tian, J.; Chen, Y. Methods of improving room temperature ductility of TiAl based alloys. Rare Metal Mat. Eng. 2003, 32, 81-86.

12. Tellkamp, V.; Melmed, A.; Lavernia, E. Mechanical behavior and microstructure of a thermally stable bulk nanostructured Al alloy. Metall. Mater. Trans. A 2001, 32, 2335-2343.

13. David, W.; Lee, Z.; Rodriguez, R.; Nutt, S.; Lavernia, E. Al-Mg alloy engineered with bimodal grain size for high strength and increased ductility. Scripta Mater. 2003, 49, 297-302.

14. Wang, Y.; Chen, M.; Zhou, F.; Ma, E. High tensile ductility in a nanostructured metal. Nature 2002, 419, 
912-915.

15. Wang,Y.; E. Ma, Three strategies to achieve uniform tensile deformation in a nanostructured metal. Acta Mater. 2004, 52, 1699-1709.

16. Lu, L.; Shen, Y.; Chen, X.; Qian, L.; Lu, K. Ultrahigh strength and high electrical conductivity in copper. Science 2004, 304, 422-426.

17. Zhao, Y.; Liao, X.; Cheng, S.; Ma, E.; Zhu, Y. Simultaneously increasing the ductility and strength of nanostructured alloys. Adv. Mater. 2006, 18, 2280-2283.

18. Lu, K.; Lu, L.; Suresh, S. Strengthening materials by engineering coherent internal boundaries at the nanoscale. Science 2009, 324, 349-352.

19. Liu, G.; Tao, N.; Lu, K. 316L Austenite stainless steels strengthened by means of nano-scale twins. J. Mater. Sci. Technol. 2010, 26, 289-292.

20. Liu, G. Microstructure and mechanical properties of nano-twins strengthened AISI 316L stainless steels, Institute of metal research. Chinese Academy of Sciences, Shenyang, 2010.

21. Yan, F.; Liu, G.; Tao, N.; Lu, K. Strength and ductility of 316L austenitic stainless steel strengthened by nano-scale twin bundles. Acta Mater. 2012, 60, 1059-1071.

22. Hosseini, S.; Alishahi, M.; Najafizadeh, A.; Kermanpur, A. The improvement of ductility in nano/ultra-fine grained low carbon steels via high temperature short time annealing. Mater. Lett. 2012, 74, 206-208.

23. Wu, X.; Jiang, P.; Chen, L.; Zhang, J.; Yuan F.; Zhu, Y. Synergetic strengthening by gradient structure. Mater. Res. Lett. 2014, 2, 185-191.

24. Wu, L.; Jiang, P.; Chen, L.; Yuan, F.; Zhu, Y. Extraordinary strain hardening by gradient structure. P. Natl. Acad. Sci. 2014, 111, 7197-7201.

25. Huang, C.; Hu, W.; Wang,Q.; Wang, C.; Yang, G.; Zhu, Y. An ideal ultrafine-grained structure for high strength and high ductility. Mater. Res. Lett. 2014, 3, 88-94.

26. Zhao, Y.; Zhou, L.; Wang, Q.; Yan, K.; Zou, J. Defects and tensile properties of 6013 aluminum alloy T-joints by friction stir welding. Mater. Design 2014, 57, 146-155.

27. Liu, C. Mechanical properties of materials. Chemical Industry Press, Beijing, 2009.

28. Alavi, F.; Behravesh, A.; Mirzaei, M. In-situ observation of fracture mechanism of wood-plastic composites in tension. Compos. Interface 2013, 20, 211-220.

29. Wang, Y. In-situ SEM observation of a micro-crack in single crystal silicon and its strain fields. Inner Mongolia University of Technology, Hohhot, 2013.

30. Zeng, H. Study on MEMS-based in-situ TEM/SEM tensile experiment on nanostructure, University of Science and Technology of China, Beijing, 2013.

31. Pan, C.; Huang, Y.; Fu, Q. "In-situ-tracking" technique and its application for material microstructure property relationship evaluations. Heat Treat. Met. 2010, 35, 1-6.

32. Huang, H.; Li, F. Study on mechanical properties of composite materials by in-situ tensile test. J. Southeast U. Eng. 2004, 20, 49-52.

33. Qi, L.; Zhang, W.; Liu, X.; Ji, L.; Chi, Q.; Xiong, Q. Analysis of plasticity deformation by in-situ means of high strength pipeline. J. Shanghai Jiaotong U. 2012, 46, 1455-1460.

34. Zhu, R.; Li, S.; Lu, Y.; Chen, C.; Wei, T.; Wang, S. Dynamic observation of TEM in situ tensile deformation of Mn8 steel. Chin. Sci. Bull. 1996, 41, 2277-2280.

35. Liu, Y. Study on the micro fracture mechanism of SiCw/2024 Al composites by TEM in situ tensile test, Institute of Metal Research. Chinese Academy of Science, Shenyang, 1994.

36. Chen, Y.; Sun, N.; Li, H.; Jia, X. Progress and application of the in-situ SEM technique. New Chem. Mater. 2012, 60, 43-45.

37. Wu, L.; Chen, F. Development of modern SEM and its application in material science. Wuhan Iron Steel Corp. Tech. 2005, 43, 36-40.

38. Xue, D. The study of the crack initiates and propagates mechanism of TC11 alloy in the forging processing. Harbin Institute of Technology, Harbin, 2008.

39. Yao, Z.; Wang, Y.; Cheng, X.; Li, S.; Wang, F. Influence of $\mathrm{Y}_{2} \mathrm{O}_{3}$ on the mechanical properties and fracture process of 93W-4.9Ni-2.1Fe alloy. Ordnance Mater. Sci. Eng. 2008, 31, 45-47.

40. Zhen, L.; Mao, J.; Sun, D.; Yang, D. SEM in situ observation of the tensile fracture behavior in an Al-Li-Cu-Mg-Zr alloy. Acta Aeronaut. Astronaut. Sin. 1993, 11, A670-762.

41. Shaoanjun, M. In situ study of oxidation on iron surface with ESEM. Acta Metall. Sin. 2000, 36, $230-234$.

42. Shao, M.; Duan, Y.; Li, H., Li, Z. Dynamic study on iron nickel oxide whisker growth with ESEM. J. Chin. Electron Microsc. Soc. 1996, 15, 540-542.

43. Jiang, H.; Mi, Z.; Tang, D.; Wang, H.; Dai, Y. In-situ observation of microstructure in TWIP steel during tensile deformation. J. Mater. Eng. 2008, 1, 38-41. 
44. Ren,T.; Wang, H. Wen, D.; Zhao, P.; Gao, X.; Li, W. Qi, C.; Huo, Y. In-situ SEM study of dynamic tensile in austenitic stainless steel 1Mn18Cr18N of retaining ring. Large Electr Mach. Hydraul Turbine 2014, 2, 28-31.

45. Wang, R.; Liu, J.; Song, Y. Progress and applications of in situ transmission electron microscopy. Physics 2015, 4, 96-105.

46. Zhang, X. Development and applications of high-resolution environmental transmission electron microscopy. J. Chin. Electron Microsc Soc. 2010, 29, 287-294.

47. Xu, T.; Sun, J.; Sun, L. Progress in dynamic in situ electron microscopy. Prog. Phys. 2012, 32, 115-134.

48. Bai, X. Nano mechanics by in situ TEM. Chin. Conf. Appl. Mech. 2005.

49. Ohr, S.; Kobayashir, S. In-situ observation of crack propagation by transmission electron microscopy. J. Miner. Metals Mater. Soc. 1980, 32, 35-42.

50. Kobayashir, S.; Ohr, S.M. In situ fracture experiments in bcc metal. Philos. Mag. A 1980, 42, 763-772.

51. Yao, K.; Tang, N.; Chen, N. In-situ observation of crack tip deformation in a duplex stainless steel. Acta Metall. Sin. 1989, 25, A213-218.

52. Hoshino, Y.; Nakamura, S.; Ishikawa, N.; Yamaji, Y.; Matsumoto, S.; Tanaka, Y.; Sato, A. In-situ observation of partial dislocation motion during $\mathrm{\gamma} \rightarrow \varepsilon$ transformation in a Fe-Mn-Si shape memory alloy. Mater. T. JIM. 1992, 33, 253-262.

53. Fujita, H.; Katayama, T. In-situ observation of strain-induced $\gamma \rightarrow \varepsilon \rightarrow \alpha^{\prime}$ and $\gamma \rightarrow \alpha^{\prime}$ martensitic transformations in Fe-Cr-Ni alloys. Mater. T. JIM, 1992, 33, 243-252.

54. Xie, J.; Zhu, Y.; Li, Q.; He, Z. Observation of medium manganese steel during TEM in-situ tension. J. Chin. Electron Microsc Soc. 1999, 18, 529-535.

55. Wu, H.; Wu, F.; Yang, S.; Tang, D. The formation mechanism of austenite structure with micro/sub-micrometer bimodal grain size distribution. Acta Metall. Sin. 2014, 50, 269-274.

56. Li, X.; Wei, D.; Cao, J.; Ye, L.; Chen, J. In situ TEM observation on martensitic transformation during tensile deformation of SUS304 metastable austenitic stainless steel. Acta Metall. Sin-Engl. 2015, 28, 302-306.

57. Wang, J.; Zeng, Z.; Weinberger, C.; Zhang, Z.; Zhu, T.; Mao, S. In situ atomic-scale observation of twinning dominated deformation in nanoscale body-centred cubic tungsten. Nat. Mater. 2015, 14, 594-600.

58. Zhang, J.; Lu, F.; Wang, Z. ; Zhao, F. Rupture behavior of 3104 aluminum alloy sheet in-situ observation by SEM. Heat Treat. Met. 2016, 41, 34-37.

59. Shi, J.; Guo, Z.; Sui, M. Slip system determination of dislocations in a-Ti during in situ TEM tensile deformation. Acta Metall. Sin. 2016, 52, 71-77.

60. Xie, D.; Li, S.; Li, M.; Wang, Z.; Gumbsch, P.; Sun, J.; Ma, E.; Li, J.; Shan, Z. Hydrogenated vacanicies lock dislocations in aluminium. Nat. Commun. 2016, 133(7), 41-60.

61. Sheng, J.; Li, J.; La, P., Wei, F., Song, Y., Wang, K. Investigation of tensile properties of 316L stainless steel with micro-nano-structure in SEM by in situ tension. Integr. Ferroelectric 2017, 181, 33-41.

62. Wang, H.; La, P.; Shi, T.; Wei, Y.; Lu, X. Research Status and development trend of bulk nano/micro-crystalline composite metallic materials. J. Mater. Eng. 2013, 4, 92-96.

63. Sheng, J.; Li, J.; La, P.; Wei, F.; Song, Y.; Wang, K. Investigating the tensile properties of micro-nanostructured 304 stainless steel with SEM and in-situ tension. Sci. Adv. Mater. 2017, 9, 1020-1027. 